\title{
CONTENTS
}

List of Illustrations ix

Preface xiii

Acknowledgments $x x i$

1 Current Matters: An Introduction 1

PART I: A NEW MATERIALIST RHETORICAL APPROACH IN THEORY

2 Spatiotemporal Matters 25

3 Agential Matters 56

PART II: A NEW MATERIALIST RHETORICAL APPROACH IN PRACTICE

4 New Materialist Research Strategies 85

5 Iconographic Tracking 106

PART III: OBAMA HOPE CASE STUDY

6 Obama Hope, Presidential Iconography, and the 2008 Election 135

7 Obama Hope, Fair Use, and Copyright 177

8 Obama Hope, Parody, and Satire 202

9 Obama Hope, Remix, and Global Activism 244

10 Future Matters: A Conclusion 281

References 297

About the Author 312

Index 313 


\section{CURRENT MATTERS}

An Introduction

Pictures want equal rights with language, not to be turned into language. They want neither to be leveled into a "history of images" nor elevated into a "history of art," but to be seen as complex individuals occupying multiple subject positions and identities.

—W.J.T. Mitchell, What Do Pictures Want?

April 27, 2006, is an important date for visual rhetoric. On this date, Hollywood actor George Clooney, Senator Sam Brownback, and thenSenator Barack Obama were holding a press conference at Washington's National Press Club. Clooney had just returned from a trip to Darfur and was publicly demanding that the US government act more quickly to stop the ongoing genocide. On the sidelines a photographer for the Associated Press (AP) sat, intending to capture photos of Clooney in an important political performance. Little did the photographer know, when he turned his camera toward Obama, that he would capture one of the most iconic images to surface in recent US history.

The photograph taken by Mannie Garcia is now familiar to those of us who closely followed the 2008 US presidential election, have paid attention to US popular culture over the last few years, or have simply passed the image captured in the photo on the street one day while walking to work. For the image in Garcia's photograph transformed into the now-iconic Obama Hope image designed by street artist Shepard Fairey (see Figures 1.1 and 1.2). The Obama Hope image in its "Faireyized" version (henceforth referred to as simply Obama Hope) entered into circulation in late January 2008 in an effort to help thenSenator Obama become the 44th US president. Today, digital manifestations and remixes of this image can be found on more than two million websites while numerous physical renditions can be found tattooed on 
human bodies, plastered to urban walls, and waving at protests across the globe. As it has circulated both within and beyond US borders, this image has played a plethora of rhetorical roles ranging from political actor to advertising agent to social critic to international activist. Today, its materialization in Fairey's Hope poster is also widely recognized as a cultural icon and national symbol. New Yorker art critic Peter Schjeldahl (2009) has gone so far, in fact, as to deem Fairey's Hope poster the most efficacious political illustration since Uncle Sam Wants You.

How has this particular image come to lead such an extraordinary rhetorical life? How did it go from materializing in one among hundreds of photographs taken at a press conference in April of 2006 to a cultural icon, national symbol, and powerful rhetorical actant in just a few short years? When asked how the Obama Hope image gained the wide recognition needed to become a cultural icon, Fairey himself said the image simply "went viral." Made popular with the boom of the Internet in the mid-to-late 1990s, "going viral" is a common means of explaining how ideas, trends, objects, videos, and so forth spread quickly, uncontrollably, and unpredictably into, through, and across human populations. Such explanation is linked to a ubiquity of tropes and concepts related to epidemiology that has become part of the US American social imaginary in the twenty-first century. As Chad Lavin and Chris Russill (2010, 67 ) have argued, this imaginary has manifested in response to an anxiety constituted, in part, by a destabilized sense of space and time produced by an unprecedented emergence of global economic and communicative networks. Deeply entrenched, this epidemiological imaginary can be thought of as "the logic of the viral," which helps makes sense of not only the spread of diseases but also the spread of culture in a networked social landscape (Seas 2012, 6). According to this logic, a thing is commonly said to be viral when it is perceived as being socially contagious due to its capacity to garner mass attention and spread via word of mouth and media. In common parlance, then, we say something like a video has gone viral based on the sheer speed at which the video has attracted a wide viewing, often, but not always, because it has circulated widely across media, been remixed, and inspired imitative spinoffs.

In an attempt to explain how something such as Obama Hope can go viral, Fairey explained in a Terry Gross (2009) interview on Fresh Air that a viral phenomenon is made possible by first creating an image that is highly desired and admired, and second, by ensuring that a broad audience has access to that image so it can be redistributed. The Internet makes viral campaigns especially possible as images and messages can reach audiences dispersed across the world in a matter of seconds. With 


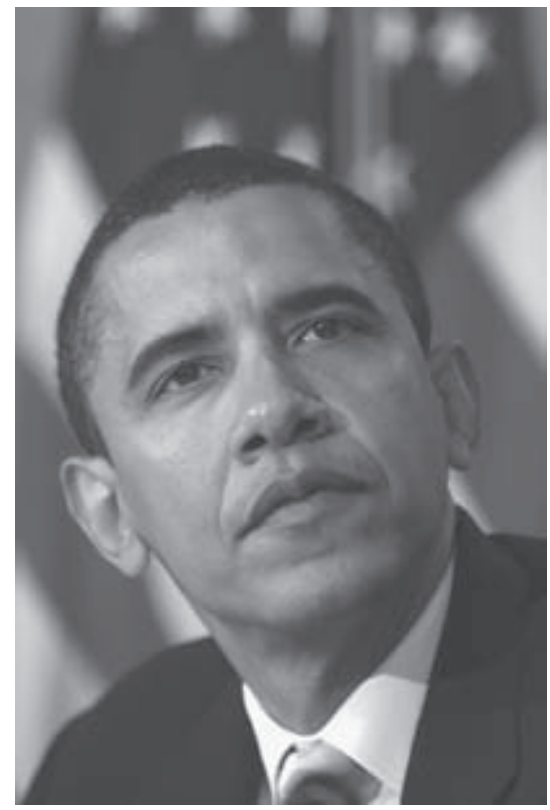

Figure 1.1. Photograph of Barack Obama, Mannie Garcia, 2006. Permissions from the Associated Press.

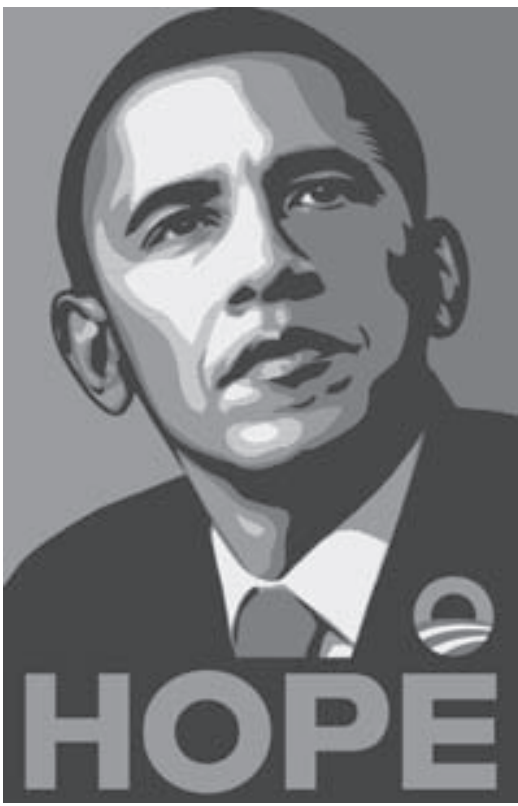

Figure 1.2. Obama Hope, Shepard Fairey, 2008. Courtesy of Shepard FaireyObeyGiant.com.

the recent emergence of YouTube, Facebook, Twitter, and other socialmedia sites, the capacity for an image and message to circulate widely has only been amplified. Thus, as an explanation of how the Obama Hope image has become a cultural icon, "it went viral" might seem like an easy-enough-to-understand answer. This answer, however, offers little theoretical and practical understanding of how images actually circulate, transform, and replicate in both physical spaces and cyberspace. In an increasingly participatory culture in which a variety of groups produce and distribute media for their collective interests (Jenkins, Ford, and Green 2013, 2), such an answer particularly elides the logics, structures, practices, collectives, and platforms that enable images to circulate and transform widely. This answer also offers little understanding of how things become rhetorical as they circulate and transform with time and space and contribute to collective life. From a new materialist perspective, things become rhetorically meaningful via the consequentiality they spark in the world. By accepting Fairey's explanation of how Obama Hope has become a cultural icon, then, we miss the opportunity to learn how an image such as Obama Hope becomes an important rhetorical 
actor as it materializes and actually effects change in our daily realities. Or in simpler terms, by accepting the explanation of "it went viral," we miss learning how Obama Hope has made and continues to make (rhetorical) history.

In one sense, this book is an attempt to get at these how inquiries. Chapters 6-9 present a four-part case study that makes visible how, since 2006, Obama Hope has influenced cultural, political, and economic materialities and thus, in Bruno Latour's (2005a) terms, "reassembled the social." However, while this book may begin with a focus on the Obama Hope image and spend much time throughout discussing its rhetorical life, throughout most of the chapters, Obama Hope ironically acts as a representative anecdote in that the theories and methods included herein have been constructed around the Obama Hope phenomenon. ${ }^{1}$ In addition, alongside other images such as the Mona Lisa and the Raised Fist, Obama Hope acts as an example to help accomplish the book's ulterior purpose. As Brian Massumi (2002) draws on Giorgio Agamben to note, the example is an "odd beast" (17). The example is one singularity among others, yet, simultaneously, the example "stands for each of them and serves for all." As a singularity, the example is neither general nor particular. It belongs to itself and simultaneously extends to everything else with which it might be connected (17-18). As both a representative anecdote and an "odd beast" in this book, then, while the Obama Hope image tells its own unique rhetorical story, the image also exemplifies what we can learn by taking a new materialist approach to studying the futurity of visual rhetoric. For another important purpose of this book is to articulate what a new materialist approach to visual rhetoric might entail and how it might contribute to rhetorical and circulation studies at large.

\section{NEW MATERIALISM}

First coined as a term in the latter half of the 1990s and independently of one another by Rosi Braidotti and Manuel De Landa, new materialism or neomaterialism is an emergent interdisciplinary theory informed by contemporary scholarship emanating from the intersections of science studies, feminist studies, and political theory. ${ }^{2}$ From a definitional standpoint, new materialism is difficult to pin down. In one sense, new materialism is not new at all in that new materialists build on the work of scholars such as Spinoza, Bergson, Deleuze, and Guattari and can thus simply be thought of as an extension of a longstanding monist tradition (Dolphijn and der Tuin 2012, 94-95). Furthermore, new materialism is 
not a unified shared inquiry, especially since it is being taken up across multiple fields such as political science, women's studies, social science, history, and, as of late, rhetorical studies. Nonetheless, new materialism can be thought of as part of a nonhuman turn ${ }^{3}$ taking place across several disciplines as scholars challenge the modernist paradigm (heavily influenced by Descartes and Kant) that perpetuates dualist kinds of thinking, which many scholars find reductive and unproductive. As Latour (1993) explains in We Have Never Been Modern, modernity tries to divide the world into separate, opposing spheres with humans/subject/ culture on one side and things/objects/nature on the other. New materialists reject such dualism, arguing that any bifurcation of humans and things, culture and nature, object and subject fails to acknowledge the ontological hybridity that constitutes reality. In order to make sense of the complex material realities we face in the twenty-first century, then, new materialists focus on what Donna Haraway (2003) has called "naturecultures," or what Latour (1993) calls "collectives," to acknowledge the significant, active role nonhuman things play in collective existence alongside a host of other entities.

New materialism, in part, is an ontological project in that it challenges scholars to rethink our underlying beliefs about existence and particularly our attitudes toward and our relationships with matter. In a broad sense, new materialists conceive of matter as vital, transformative, and morphogenetic; in this sense, as Tianen and Parikka (2010) have argued, matter is both "self-differing and affective-affected." New materialism is also a philosophical project as it works to develop new concepts that can help develop new insights about collective matters. In any tradition of inquiry, a common discourse is needed so scholars can communicate and build on each other's knowledge. As such, new materialists are developing a lexicon filled with neologisms such as intra-action ${ }^{4}$ and new concepts such as body multiple ${ }^{5}$ that push us to think otherwise about matters we tend to take for granted. Yet new materialism is also a methodological project. Like all parties involved in the nonhuman turn, new materialists critique linguistic and social constructivisms and "the overconfidence about human power that was inadvertently embedded in the postmodernisms of the 1980s and 90s" (Bennett 2012). Karen Barad (2007), perhaps, states this problem best: "Language has been granted too much power. The linguistic turn, the semiotic turn, the interpretive turn, the cultural turn: it seems that at every turn lately every 'thing'even materiality-is turned into a matter of language or some other form of cultural representation" (132). As such, new materialists are developing new modes of analysis that give "material factors their due in 
shaping society and circumscribing human prospects" (Coole and Frost 2010, 2-3), modes that often offer a broader and messier perspective than representational approaches typically offer.

New materialism is motivated to a great extent by an emergence of complex phenomena such as climate change, genetically modified foods, and ewaste, all of which are constituted by a complex, dynamic assemblage of intermingling and historically produced discursive, material, natural, social, technological, and political actants-an entanglement that Andrew Pickering (1995) might call a "mangle." But new materialists recognize that mangles are not specific to such recent phenomena of pressing concern. As Susan Hekman (2010) notes so succinctly, "Mangles are everywhere. They construct the world we inhabit in all of its complexity" (126). Such complexity cannot be investigated via methodologies that give too much weight to language's ability to account for reality, agency, and ontology. Nor can such complexity be "understood in the modern metaphysics that distributes Nature and Society into pure ontological zones ... and allows us to disavow our responsibility for the consequences of our sociotechnical activity" (Herndl 2012). For new materialists, then, new kinds of empirical investigations that foreground distributed relations and attend to the nonlinear processes of materialization are needed to make sense of our contemporary existence. In a manifesto-like tone, Diana Coole and Samantha Frost (2010) claim that, in fact, "foregrounding material factors and reconfiguring our very understanding of matter are prerequisites for any plausible account of coexistence and its conditions in the twenty-first century" (2).

Across the humanities, new materialist approaches such as Jane Bennett's work with vital materialism and Barad's and Hekman's feminist work with agential realism and social ontology, respectively, are emerging to help give material factors their due. While each mode of inquiry is distinct, all consider reality to be collectively, materially, and semiotically constructed via a variety of actants that have equal ontological footing. New materialists thus acknowledge the vital and transformative characteristics of matter-characteristics typically reserved for humans alone. In this agential sense, new materialists embrace what Levi Bryant (2011) refers to as "parity reasoning" — a form of reasoning that, in refusing to grant one sort of agency control of development, emphasizes distributed causality (201). Thus, while discourse clearly plays a role in many phenomena, parity reasoning forces new materialist scholars to extend their analysis to a variety of different causal factors in any given phenomenon (202). Here, then, agency becomes a distributed enactment of entangled things intra-acting within phenomena 
(Barad 2007, 235). In addition, such new materialist scholarship insists on investigating "materialization as a complex, pluralistic, relatively open process" (Coole and Frost 2010, 7). As such, the notion of becoming that is found in process philosophies undergirds many new materialists' sense of time and space. Such materialization will be explained in more detail in chapter 2 in order to help readers better understand the theories driving the new materialist notions offered herein. Important to simply note here is that because matter is conceived of as a productive, dynamic, and resilient force that shapes reality, new materialists take things—stuff, if you will-seriously. New materialists specifically wonder, "What happens when the "propensities, affordances, and affectivities of nonhumans' are included in the action of assembling our collective common world?" (Herndl 2012).

Still Life with Rhetoric argues that such inquiry is productive for rhetorical and circulation studies at large, but it is especially important for visual rhetoric. Instrumentalist frameworks of rhetoric often focus on human agents producing and delivering persuasive discourse in a situated context to an immediate audience (at the very least in the imagined sense). Rhetoric, in this framework, is conceived as not only the faculty one has to create and deliver a persuasive object of some sort but also as the object itself, whether it is delivered in the form of a speech, a text, or a picture. In such latter cases, rhetoric is thought about in the transitive sense (Brooke 2009, 176). Much like everyday products, rhetoric is an already-produced and already-delivered object. Hence, in visual rhetoric, much scholarship is synchronic in that it focuses on the still life of rhetoric and works to identify how an already-materialized image makes communication and persuasion possible in a limited snapshot of time. As Obama Hope's rhetorical life makes visible, however, rhetoric is not as still as we may think. Rhetoric prevails beyond its initial moment of production; once unleashed in whatever form it takes, rhetoric transforms and transcends across genres, media, and forms as it circulates and intra-acts with other human and nonhuman entities. Rhetoric also moves in nonlinear, inconsistent, and often unpredictable ways within and across multiple networks of associations. In addition, as rhetoric becomes part of various collectives, a multiplicity of often unforeseeable affective and rhetorical consequences materialize that, in turn, spark other consequences. As such, rhetoric, especially in a digitally mediated environment, is more like an unfolding event-a distributed, material process of becomings in which divergent consequences are actualized with time and space. In this intransitive sense, rhetoric is everything but still. Many studies of visual rhetoric simply do not acknowledge that 
once rhetoric is initially distributed, there is still much life with rhetoric and thus neglect to account for this dynamic eventfulness.

In light of this neglect, this book argues that more work ought be done to empirically disclose how things such as Obama Hope and its various materializations become rhetorical in diverse ways as they flow, transform, and alter multiple realities. We need, in other words, to turn our scholarly gaze toward futurity-the time spans beyond a thing's initial production and delivery-and create risky accounts of how rhetoric unfolds as things enter into complex associations and catalyze change. Only with an eye toward futurity can rhetoricians, working in a digitally networked culture, actually account for how things circulate, take on a life of their own, and help constitute and reconstitute collective existence.

\section{WORKING DEFINITIONS}

Before I move forward any further, I ought to probably pause here to define a few key terms that ground this methodological project. Just as I conceive of rhetoric in distinct ways that may differ sharply from how others think of it, I must also make transparent how I think in particular ways about life, visuals, images, pictures, and things in relation to rhetoric. Throughout the book, I use the word life to refer to things' complex and intense vitality. I specifically employ life in an effort to challenge our anthropocentric notions of rhetorical agency-a position to be further discussed in chapter 3-and acknowledge the active contributions things make to collective existence. Christopher Pinney (2005) argues that using life in reference to nonhuman things runs the risk of perpetuating a "human besotted vision of reality" (259). When I use life to in relation to things, he might argue, I actually fail to move beyond anthropocentric notions of materiality. However, while such risk is noted with concern, moving beyond anthropocentric accounts of materiality is impossible, as we can never get outside human consciousness even if we can acknowledge that things exists on their own accord. What we can do, however, as I articulate in chapter 5, is create less asymmetrical accounts of rhetorical activity in our scholarship, recognize the intimacy we share with nonhuman things, and acknowledge the vital force things exert in reality. As such, I follow W.J.T. Mitchell's (2005) lead and embrace the term life anyway to acknowledge the vitality of things that we too often deem far too inert.

In terms of visual rhetoric, I attempt to consistently use the words visuals, images, and pictures in distinct ways throughout this book. While 
these terms are often used interchangeably, I believe it is important to acknowledge their distinction and make more concerted efforts to establish consistency across our scholarship so as not to confuse our readers. In a general sense, I consider a visual to be "that which we think we see" whether that is interpreted as an alphabetic letter or a cloud or a political poster. Anne Marie Seward Barry (1997) explains that "that which we perceive" is never reality; it is always a mental configuration that emerges as an end result of a complex perceptual process that begins with a detection of light in the eye and proceeds as different parts of the brain interpret electrical signals that represent the environment" (37). Barry actually calls such mental configuration an "image," but as a visual rhetorician writing about a specific image in this book, I find it useful to save image for a more specific immaterial thing that actualizes in various concrete forms and think of visuals in the broader sense as that which we see. In this book, then, I use the term visual as an adjective only so as not to create confusion and instead speak of images and pictures as nouns, and, more specifically, two distinct kinds of visual things.

Let me explain this distinction in more detail by drawing heavily on the work of W.J.T. Mitchell. In "Visual Literacy or Literary Visualcy?" Mitchell (2009) explains that the distinction between images and pictures could be understood in the phrase "you can hang a picture but you can't hang an image" (16). According to this line of thinking, a picture is an image that "appears in a material support," which includes photographs, posters, digital reproductions, murals, or other material things. (16). An image, on the other hand, can be conceived of as "an immaterial entity, a ghostly, fantasmatic appearance that comes to light or comes to life (which may be the same thing) in [such] material support" (18). An image, then, in simpler terms, is that which appears in a picture and survives a picture's destruction, as it is able to transcend media (16). In this sense, an image, while highly abstract, can be evoked in word as long as recognition takes place (17). It is recognized because it resembles something familiar to us, whether that thing is a physical entity that a materialized image (picture) depicts or something, mental or physical, that is entirely different yet has some familiar attribute.

Mitchell offers the example of the clone to clarify the image/picture distinction. But for this book's purposes, take a look at the collage in Figure 1.3 consisting of six pictures, in all of which the Obama Hope image has materialized. In some pictures, Obama Hope materializes in similar, even seemingly exact, ways as it did in Fairey's Hope poster and is thus easily recognizable if you are familiar with Fairey's work. Yet in other pictures, such as Matt Sesow's painting Rhetoric in the upper right-hand 

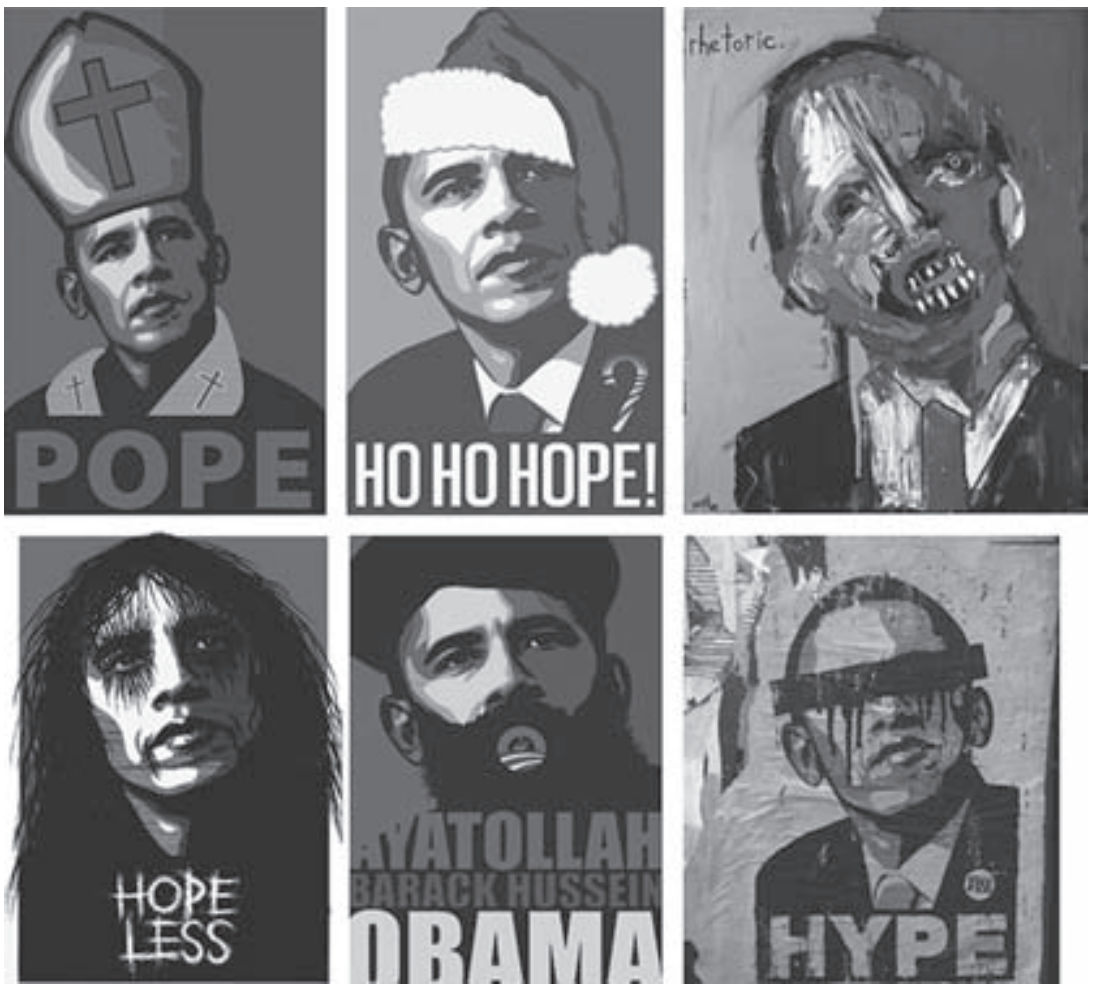

Figure 1.3. Collage of Obama Hope remixes. ${ }^{6}$ Pictures courtesy of Filippo Marongiu (top left), Matt Cornell (top middle), Matt Sesow (upper left), Klutch (lower left), Shahab Siavash (lower center), and Pablo Perez (lower right).

corner and Klutch's Hopeless in the bottom-left corner, Obama Hope is barely recognizable. One must be intensely familiar with the specific colors, style, arrangement, and content of Obama Hope to recognize its presence. Nonetheless, as is evident here, the Obama Hope image haunts and transcends all these pictures. When I speak of visual things in this book, then, I am referring to both an image and the various material supports in which an image comes to life. ${ }^{7}$ And, more specifically, when I speak of Obama Hope, I am referring to the image that first actualized in Garcia's photograph but more typically is associated with Fairey's red, white, and blue stylized rendition of Obama's portrait that materializes in a wide range of different pictures and on a wide range of things, sometimes in relation to a word such as hope and other times not.

Also important to note here is that both image and picture are real things in that both stimulate actual material consequences. To 
understand an immaterial thing, it might be useful to think of an image as being virtual (Vivian 2007). As will be discussed in more detail in chapter 2, virtual entities cannot be physically touched like an actual thing such as a painting or poster. Yet virtual entities do not just exist and circulate in cyberspace either. As Gilles Deleuze (1994) helps us understand, the virtual is "the characteristic state of ideas; it is on the basis of reality that existence is produced, in accordance with a time and space that is immanent in the Idea (211). The virtual, it might be easiest to understand, is a potential thing that, via the process of materialization, or in Deleuze's term "actualization," becomes a material force. As will be made evident by a four-part case study of Obama Hope, virtual things spark material consequences in all kinds of ways. In this book, for instance, the Obama Hope image comes to life both in a variety of pictures and in the words I use to describe its circulation, transformation, and consequentiality. Thus, even as I have never encountered the physicality of the image itself, Obama Hope is an active actant in that it has, among other things, deepened my understanding of rhetoric and shaped my thoughts and actions in all kinds of intense ways for the last four-plus years. While an image is virtual, immaterial, then, it is also a real thing that sparks traceable consequences in the world.

Now, in relation to thing, as readers might have already gathered, I specifically employ this term throughout the book to draw attention to the materiality of visual artifacts, which become rhetorical with time and space as they spark a diverse range of consequences. By rhetorical, I refer to something's ability to induce change in thought, feeling, and action; organize and maintain collective formation; exert power, etc.; as it enters into relation with other things (human or nonhuman). I resist the notion that something is rhetorical just because it has been intentionally created to persuade and has been delivered to a particular audience with that intended goal in mind. Instead, my understanding of rhetoric is that all things have potential to become rhetorical as they crystallize, circulate, enter into relations, and generate material consequences, whether those consequences unfold in conceptual or physical realms. Rhetoric here, then, is conceived of as a virtual-actual event that unfolds with time and space as things-whether they be images, pictures, books, movies, rocks, trees, or animals-enter into material relations with humans, technologies, and other entities. In one sense, as part 1 of this book elucidates, rhetoric, as a disturbed event, comes into existence from signs-in-use, from discourse conceived in its broadest sense. However, I worry that speaking about images and pictures in terms of discourse places too much emphasis 
on signification and too little emphasis on materiality, transformation, and consequentiality.

In addition, while I do focus on visual things produced by humans in this book, I do not believe that rhetoric is the specific domain of human language. ${ }^{8}$ This sentiment is much aligned with Wayne Booth's (1974) thoughts about rhetoric as articulated in a footnote in Modern Dogma and the Rhetoric of Assent:

There is a sense in which even the lowest animals can be said to intend meanings or to influence the rest of the world rhetorically; I would not even resist defining the universe as essentially rhetorical: it is created, as Whitehead says, in processes of interchange among its parts. Each least particle-whatever that turns out to be-just like each gross beast and 'dead' star, could be defined as a steadily changing 'field of influences,' receiving, processing, and transmitting 'information.' (126).

While Booth suggested in this same footnote that such perspective of rhetoric "takes us nowhere" and turns "rhetorical influence" into a "foggy metaphor," I argue the contrary. From a new materialist perspective, thinking about things' rhetorical influence takes us everywhere, and while we are hesitant to follow this path in the name of human exceptionalism, new materialism, with its focus on relationality and posthumanism, can help us forge this difficult yet promising path. As Scot Barnett (2010) has drawn on Graham Harman to argue, we can study "rhetoric as both a human art and an ontological condition potentially operable alongside human beings in the world's vast and inexhaustible carpentry of things" (my emphasis). ${ }^{9}$ When writing about images and pictures in this book, then, I most often use things, rather than discourse, ${ }^{10}$ in order to help reimagine the traditional boundaries of rhetorical study. I specifically draw on Bennett's vital materialist understanding of things and Latour's definition of thing to emphasize the way rhetoric emerges from the material relations and activities that unfold as a diverse ecology of nonhuman and human things assemble and intraact in various collectives.

As I will discuss in more detail in chapter 3, things acquire power to shape reality as they become entangled in complex relations with humans and other nonhuman entities. Too often, we miss the opportunity to acknowledge the force of things because we assume they are inert tools used by human agents whom we typically credit with full-blown agency. Yet, if we study a thing with a new materialist sensibility, we can recognize its thing-power-the power things acquire when working alongside other entities to produce change, even as they all have different degrees of power (Bennett 2010). One major kind of change that is 
important for this book is the ability to reassemble collective existence. As Latour (2005a) explains, thing as defined in the English dictionary originally designated a type of assembly. Still in such use in many Nordic and Saxon nations, thing has meant an issue that brings people together even as it may divide them in the process (13). Things such as Obama Hope often provoke and engage in assemblage because they attract entities that are aligned with and want to work toward similar goals, but things also induce and participate in assemblage because of divisive matters. In addition, no matter the reasons for assemblage, assemblages are always in flux as participating entities move in and out of assemblage. In thinking about visual things, then, we are not only reminded of rhetoric's ability to induce cooperation, as Kenneth Burke emphasizes, but also to induce assemblage (and reassemblage). In this sense, things such as the Obama Hope image become rhetorical, in part, as a consequence of their emergent ability to mobilize various entities into relation, help materialize change, and thus reassemble collective existence.

In addition, thinking about images as visual things cultivates attention to what Latour calls "matters of concern." As Latour (2005b) explains in Reassembling the Social, "To be 'treated like things'. . . is not to be 'reduced' to mere matters of fact, but allowed to live a life as multifarious as that of matters of concern" (255). As matters of fact, things are considered to be transparent, obvious, discrete objects easily taken for granted. They are not complicated, as Latour (2004) draws on Ludwik Fleck to explain: "They are never simultaneously made through a complex history and new, real, and interesting participants in the universe" (159). As matters of concern, things are more elusive and provocative; they are dynamic, complex entanglements that often change right before our very eyes as they experience new associations. In this sense, things are more like phenomena. As such, they cannot be easily identified nor understood as they are mediating, assembling, and gathering many more folds that could be detected if considered to be already delivered (Latour 2004, 173). However, as matters of concern, things force us to acknowledge that the things with which we are so closely enmeshed may be what Timothy Morton (2012) has identified as "strange strangers" (17), but they nonetheless acquire mediational potential to shape all kinds of matters-political, emotional, psychological, relational, familial, and so forth-via their dynamic relations with human and nonhuman entities. We may not be certain as to how this mediation occurs, but that is precisely the point. In wondering how visual things become rhetorical, we are encouraged to seek out the dynamic, consequential, unfolding, and mediated activities that enable visual rhetoric to manifest 
and impact reality. Rather than be certain that this thing is rhetorical in this way and this time and space, then, this new materialist rhetorical approach seeks to empirically discover how an image becomes rhetorical in divergent ways as it circulates with time, enters into new associations, transforms, and generates a multiplicity of consequences-a process I call rhetorical transformation.

\section{THE FUTURITY OF RHETORIC}

In order to account for rhetorical transformation, this new materialist rhetorical approach turns the scholarly gaze mostly toward futurity. By futurity, I am referring to the strands of time beyond the initial moment of production and delivery when rhetorical consequences unfold, often unpredictably, as things circulate and transform across space, form, genre, and function. In terms of research, a new materialist rhetorical approach advocates for conducting empirical investigations to make transparent what happens not only to an image but also to the people and other entities an image encounters when they all enter into complex relations. A new materialist rhetorical approach recognizes that this "happening" occurs before and while an image is being produced. However, in order to account for a thing's complex rhetorical life, this approach is most interested in what happens after the image is initially produced and distributed. To account for this unfolding eventfulness, methods such as iconographic tracking can take a new materialist rhetorical approach and attend to seven distinct yet co-implicating material processes: composition, production, distribution, circulation, transformation, collectivity, and consequentiality. Such scholarly attention can help disclose how an image undergoes recomposition, reproduction, redistribution, and reassemblage, which intensify the circulation, transformation, and consequentiality of not only that image but also its derivatives. As will become clearer in part 2, when conducting iconographic tracking, these processes are not taken up in a linear, chronological fashion. Yet, in order to generate complex, ontological accounts of an image's distributed rhetorical becomings, all these processes are attended to throughout the research process.

Developing such an empirical and dynamic understanding about rhetoric demands turning to models of communication and rhetoric and developing new approaches that can help recover rhetoric's dynamic materiality, movement, and consequentiality. As Jenny Edbauer Rice (2005) notes in "Unframing Models of Public Distribution," oversimplified models of communication and the rhetorical situation model 
do not capture how rhetoric unfolds in public life. Publics are created and maintained by circulating discourses that unite strangers in a real or abstract sense (Warner 2002). Models that present communication in triangulated terms of sender, receiver, and text cannot account for the dynamic movement of discourse nor the divergent networked activity that takes place to make possible public communication. The rhetorical situation model is meant to complicate such communication models by emphasizing and exploring the contextual dimensions of rhetoric (Edbauer Rice 2005, 6). However, this model tends to position rhetoric as emanating from or being produced within a rather static scene constituted of entities perceived as already formed, stable, and discrete (Biesecker 1989; Edbauer Rice 2005; Krause 1996; Phelps 1988). In reality, the discrete elements typically accounted for in the rhetorical situation-audience, rhetor, exigence, constraints, textoperate in, as Louise Wetherbee Phelps (1988) puts it, a "flux" (60), or as Edbauer Rice (2005) puts it, a "wider sphere of active, historical, and lived processes" (8).

Rhetoric is also an emergent process distributed across a complex web of physical, social, psychological, spatial, and temporal dimensions (Edbauer Rice 2005, 12-13; Syverson 1999, 23) - a contingent process that becomes ever more complicated in a viral economy made possible by the Internet and other digital technologies. Writing in 1996, Steve Krause argued that components of the Internet such as listserves and newsgroups "facilitate and encourage situations in which multiple rhetors and audiences participate, dramatically problematizing the origins of discourse and the definitions of 'rhetor' and 'audience' presumed of classical and modern rhetorical situations." With the proliferation of the World Wide Web, social networking sites, blogs, electronic news and information sources, digital file hosting services, and so forth that make possible a viral economy, this problem is only exacerbated as the circulatory range, consequentiality, and thus force of rhetoric intensifies with each new encounter. As Edbauer Rice (2005) puts it rather bluntly, “(Neo)Bitzerian models cannot account for the amalgamations and transformations - the viral spread-of this rhetoric within its wider ecology" (19). With a tendency to focus on the predictable effects of rhetoric, such models especially cannot account for the unforeseeable material consequentiality that unfolds as things such as the Obama Hope image go viral and become rhetorical beyond a creator's own anticipation and imagination. We thus need, as Amy Propen (2012) has also recently argued, new models that can better account for the material and spatial dimensions of rhetorical things. 
Edbauer Rice's rhetorical ecology model is useful in this regard as it has potential to account for the distributed emergence and ongoing circulation of rhetoric. This model also has potential to account for the transituationality and the divergent transformations rhetoric experiences within a viral economy. However, generating such models is not enough to account for how rhetoric unfolds in a highly networked, digital culture. We also need, as Edbauer Rice (2005) herself argues, to continue working hard to develop and deploy new concepts (or recuperate and/or appropriate older ones) in order to theorize how rhetoric materializes, moves, transforms, replicates and, especially, how publics, or I would prefer collectives, materialize in relation to such distributed rhetorical activity. These new concepts are especially necessary in the case of visual rhetoric, which, as I discuss in subsequent chapters, has potential to spark contagious desires that consciously and unconsciously draw people into collective activity. While scholars such as Tony Sampson (2012) have drawn on Tarde's work to produce theories of virality that help explain how such social contagion occurs in a networked culture, visual rhetoricians can do their part by producing theories about how images contribute in unique ways to such contagious phenomena. Such theories can only develop from empirical research that can "testify" to such rhetorical contagion (see also Edbauer Rice 2005). Thus, in addition to embracing a rhetorical ecological model, we must develop new research methods that can empirically account for the distributed, contingent, and contagious process of visual rhetoric. Still Life with Rhetoric attempts to be useful in this regard by turning to the futurity of rhetoric and articulating how we can account for the circulation, transformation, and consequentiality of things in both theory and practice.

\section{AN ARGUMENT FOR CIRCULATION}

While scholars such as Cara Finnegan, Lester Olson, Robert Hariman and John Lucaites have studied circulation in relation to visual rhetoric, not all scholars applaud this move. In their forward to the 6.2 issue of Enculturation, for example, Kevin Deluca and Joe Wilferth argue that circulation, as a concept for making sense of visual things, is "dependent on habits of analysis indebted to print, calling for the studious gaze of the academic and reinstantiating the print perspective" (para. 13). As evidence, they point out that when Cara Finnegan (2003) tries to account for the rhetorical circulation of FSA photographs in her book Picturing Poverty, she tends to "skew photographs into objects palpable for a print gaze" (para. 13) and read them within a limited context. Such turn to 
circulation and contexts is an act of a taming, in Roland Barthes's terms, that "enables us to turn our eyes away from the madness, excess, and ecstasy of the singular photograph (para. 6). Because such taming "inevitably eclipses the intractable immanence of images" (para. 6), DeLuca and Wilferth argue that such an approach rarely captures an image's rhetorical force nor acknowledges its ontological status. Thus, while they praise Finnegan for attempting to do something different with photographs by attending to circulation, they advocate for letting go of "the mindset and methods of print" (para. 11), studying image as a dynamic event, and adopting a more image-oriented approach that can capture an image's complex ontology and emergent character.

As is evident in my commitment throughout this book to attend to rhetoric's dynamic eventfulness, I greatly appreciate and even take up DeLuca and Wilferth's productive challenge. Images, like music, often flow in and across a wide and diverse range of physical and digital ecosystems once they are distributed in networked pathways (Hawk 2011, 171). As images become part of new associations and transform in genre, medium, and form at seemingly simultaneous rates, divergent materializations arise with time and space. Furthermore, as an image and its various renditions intra-act with human and nonhuman entities, a multiplicity of diverse, and often unpredictable, affective and rhetorical consequences materialize. In a viral economy, as already noted, the rhetorical force, circulatory range, and dynamic transformation of images only intensify. Especially as visual things such as Obama Hope spread across networked environments, images do experience, as Derrida (2002) puts it, “an absolute arrival.” DeLuca and Wilferth's call for studying image as event is thus a necessary move if scholars want to recover rhetoric's dynamic, distributed, and contingent qualities and unpredictable contributions to collective life.

Studying an image's eventfulness is also necessary for addressing the complexities of visual production, distribution, and circulation brought on by a viral economy. As is evident in recent debates about two controversial congressional bills, SOPA (Stop Online Piracy Act) and PIPA (Protect Intellectual Property Act), as well as in recent debates about fair use in relation to Obama Hope, our current digital landscape is characterized by "drastic changes in delivery," rising debates over intellectual property, and an increasingly complex politics of publication and distribution (DeVoss and Porter 2006, 201). Consequently, scholars must interrogate the ethical dynamics of production and delivery brought on by the Internet, especially in relation to the economies of textual and image production (DeVoss and Porter 2006, 194). Scholars also must 
better account for how different kinds of collective actions influence viral circulation on the web. While authors and artists can attempt to account for rhetorical velocity by anticipating the third-party recomposition of their own work (Ridolfo and DeVoss 2009), they can never fully control where or how the things they produce will circulate. Things, especially in a digital age, simply, or rather complexly, flow. We need methods that can explain how new media practices enable things to experience reproduction and redistribution and thus circulate widely at viral speeds. We especially must better account for how digital technologies, participatory media platforms, and various actor networks contribute to the circulation and transformation of things in both digital and physical realms. In both theory and practice, then, studying the dynamic eventfulness of visual rhetoric is useful as it helps address the economic and methodological complexities brought on by a digital age.

Unlike DeLuca and Wilferth's work, however, Still Life with Rhetoric does not advocate for moving away from circulation if we want to account for a single image's complex and distributed ontology. Circulation, as a way of making sense of rhetoric, is not intrinsically linked to the habits of reading and contextualizing that DeLuca and Wilferth take issue with, nor is it inherently a transcendent category that automatically leads scholars to "corral images, interpret images, or give us their meaning" (para. 13). As I touch upon in the following chapter, these methodological habits of meaning making are deeply embedded in rhetorical study due to contemporary influences of semiotics (Goggin 2004), cultural materialism (Trimbur 2000), and rhetorico-hermeneutics (Sanchez 2006). They are also heavily informed by a longstanding tradition of representationalism that has gotten transposed onto studies of visual rhetoric (Vivian 2007). A representational framework presumes that visual artifacts can be conceived of and studied as visual language with potential to both refer to and distort that which is being described. Working under such presumption-as DeLuca and Wilferth themselves note-scholars tend to "reduce images to representations of the real" and confine them to regimes of representation (para. 15) - a reduction and confinement that eclipses their ontological complexity.

In addition, as they manifest in photographs, posters, and so forth, images appear before us like buildings and books-as stable things that have already been built and delivered. As such, we not only have a habit of studying images much like we read books (DeLuca and Wilferth 2009, para.13), but we also tend to treat them as language-like symbols that lack power unless scholars intervene with their own explanations of intention, meaning, and significance (Marback 2008). Rather than give 
images their due by fully acknowledging the distinct ways each image uniquely experiences rhetorical transformation and contributes to collective life, scholars thus tend to put images into limited contexts to help make rhetorical sense of that agential and dynamic event that so often eludes us. As a consequence of such transcendent and synchronic research habits, we often "narrow and limit the [image's] projection" (Marback 2008, 64) and do sometimes end up, as Wilferth and DeLuca claim, "eras[ing] the event in favor of interpretation" (para. 8). The heart of the problem DeLuca and Wilferth seem to be concerned with, then, has less to do with circulation in and of itself than with habits of method that constrain our ability to adequately account for rhetorical transformation and circulation in a viral age. While I share this methodological concern, I think we must be careful about unnecessarily marrying circulation to such representational and synchronic habits of study.

Circulation, as defined herein, refers to spatiotemporal flows, which unfold and fluctuate as things enter into diverse associations and materialize in abstract and concrete forms. From a new materialist perspective operating in conjunction with a rhetorical ecology model, things must be studied as divergent, unfolding becomings in order to account for their unique, distributed rhetorical ontology. Circulation is at the heart of this process, especially for new media images. Not only are the intuitions and feelings that drive an image's rhetorical productions and subsequent activities always in flux (Rice 2011, 12), but, especially in an age of viral media, once they are produced and distributed in a networked pathway, and enter into both physical arenas and cyberspaces, images rapidly undergo change in terms of location, form, media, genre, and function. In addition, as metaculture erupts from an actualized image's encounters with humans and other entities, images are often catapulted back into flow in divergent directions and generate even more configurations, which themselves often spur more circulation, transformation, and consequentiality. Thus, if we want to begin to understand how visual things spread and become rhetorical with time and space, we cannot help but acknowledge an image's ephemerality and mobility ${ }^{11}$ and attend to an image's decentralized transformation and circulation.

In addition, methodologically speaking, by helping us tune in to rhetoric's flux and flow, circulation has proven productive for pushing scholars to trace and follow things' dynamic movement. In her work with RAWA, for instance, Mary Queen (2008) models how we can trace the transformations of continually evolving, yet materially bound, rhetorical actions through the "links embedded within multiple fields of circulation" (476). By tracing an iconic photograph's history of official, 
vernacular, and commercial appropriations and following how it is reproduced, highlighted, altered, and/or parodied, Robert Hariman and John Louis Lucaites (2007) also model how attention to circulation helps account for the role of photographic icons in public culture (29). While I would agree with DeLuca and Wilferth (2009) that, in the latter case, Hariman and Lucaites do undercut the rhetorical force of images by reading them within a liberal-democratic context, such scholarship, alongside Queen and others, models how tracing the constant transformation of things can be a productive research strategy for acknowledging rhetoric's dynamic dimensions. Such a strategy is especially useful for visual rhetoric in that it helps make visible how the complex, distinct rhetorical life of a single multiple image unfolds. As I discuss in chapters 4 and 5, when we follow the circulation of an image's transformation and trace its collective activities via digital research, for example, we can begin to disclose how images such as Obama Hope become part of overlapping assemblages and participate in divergent rhetorical activities. Such collective activity often strays far beyond its imagined function and can only be tapped into by following a particular image in and out of assemblage and tracing its lively encounters. Thus, in terms of method, circulation is also important as it helps cultivate the habitus of following an image in flow and tracing its rhetorical activities to help disclose how visual things co-constitute collective life.

With this respect for circulation, then, Still Life with Rhetoric aims to show that if we think intuitively and ecologically about rhetoric and commit to creating symmetrical accounts of rhetorical activity, studies of circulation actually do have potential to disclose how rhetoric unfolds as a complex, distributed event. This is not to say that studies of circulation alone can help account for the complex ontology of a single image or any other thing in an "age of contagion" (Sampson 2012, 3). We must also attend to the ways things are composed, produced, distributed, and transformed as well as the ways they induce assemblage, spark collective action, and catalyze change that registers on affective and rhetorical dimensions. Also, such work does demand taming our representational and synchronic habits of reading, as DeLuca and Wilferth (2009) seem to suggest. Yet, more precisely, such work demands supplementing these ways of meaning making with other approaches than can follow a single thing's dynamic movement and trace its distributed materiality and consequentiality. Rather than move away from circulation in visual rhetoric, then, what if we hyperfocus on an image's constant flow and transformation and try to account for a single multiple image's ${ }^{12}$ distributed rhetorical becomings? This is the central inquiry that drives Still Life with Rhetoric. 


\section{Notes}

1. See Kenneth Burke's (1969) Grammar of Motives for how representative anecdotes are "something around which an analytic vocabulary is constructed" (59).

2. See Dolphijn and der Tuin's (2012) "The Transversality of New Materialism" in New Materialism: Interviews and Cartographies.

3. The "nonhuman turn" was the theme in 2012 for the annual conference put on by the Center for 21st Century Studies at the University of Wisconsin-Milwaukee. According to the program, new materialism, as it is taken up in feminism, philosophy, and Marxism, is working alongside various different intellectual and theoretical developments such as actor-network theory, affect theory, animal studies, assemblage theory, new brain sciences, new media theory, varieties of speculative realism, and systems theory.

4. Invented by Karen Barad (2007), intra-action is a neologism that recognizes that the boundaries and properties of all involved entities become determinate with time and space and within phenomena. This concept is also discussed in detail in chapter 3.

5. Body multiple is Annemarie Mol's (2002) term for designating the ontological multiplicity of an object. This concept is discussed in chapter 2.

6. Filippo Marongiu's Pope Obamicon, Matt Cornell's Hobama Obamicon, Matt Sesow's Painting Rhetoric, Klutch's Hopeless Obamicon, Shahab Siavash's Ayatollah Obama Obamicon, and Pablo Perez's Photograph Obama Hype have all been reprinted courtesy of the artists.

7. In writing this book, I struggled when drawing on others' work to talk about images and pictures because authors often define image, visual, and picture differently than I do. In order to not confuse my readers, I try to adhere to the way authors define and deploy image, picture, and visual when recounting their ideas. Yet, whenever I am presenting my ideas, I stick to the definitions offered in this introduction.

8. I want to thank Collin Brooke (2015) for turning me on to this quote from Wayne Booth (1974). See Collin's article, "Bruno Latour's Posthuman Rhetoric of Assent" (forthcoming in The Object of Rhetoric: Assembling and Disassembling Bruno Latour, edited by Nathaniel Rivers and Paul Lynch).

9. For other rhetorical scholars pursuing similar observations about rhetoric, see, among others, Nathaniel Rivers's (2014) "Tracing the Missing Masses: Vibrancy, Symmetry and Public Rhetoric Pedagogy" as well as Alex Reid's (2012) video in Internations, "What is Object Oriented Rhetoric," and Barnett's and Boyle's (2015) forthcoming edited collection Rhetorical Ontologies: Rhetoric through Everyday Things.

10. In subsequent chapters, I attempt to respect the way other scholars use terms such as discourse and object by using their exact terms when describing another scholar's own perspective about visual rhetoric.

11. As Mary Queen (2008) reminds us, electronic texts "change not only because they are ephemeral—forming and dissolving simultaneously—but also because they are mobile: they circulate, and, in the process of circulation, they encounter and are transformed by other forces" (475).

12. As I draw on Aarie Mol's (2002) scholarship to articulate, a single multiple image is one that is able to materialize in divergent actualizations yet simultaneously maintain a recognizable whole. See chapter 2 for more on single multiple images. 